\title{
Reseña bibliográfica: Antinucci, F. (2017). Especias. Una historia de descubrimiento, codicia y lujo, Buenos Aires: Edhasa, 142 pp.
}

Palabras claves: Especias - Gastronomía - Historia del lujo - Expansión europea

Keywords: Spices - Gastronomy - History of luxury - European expansion

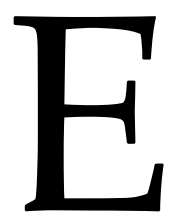
1 presente libro se encuentra a medio camino entre esos dos campos tan recelosos como disputados: la escritura académica y la divulgación histórica. Hay que leerlo en su especificidad. Se trata del ejercicio histórico-ensayístico de un académico especializado en otra área, ${ }^{1}$ amante de la gastronomía. Esto no implica que el libro falle en lo que se propone. Es pertinente en la mayor parte de lo que se plantea exponer, aunque sin dudas el lector académico encontrará incomodidad en ciertas faltas de precisión, tales como los mapas meramente ilustrativos del texto (sin referencia alguna) y en las ausencias de notas y referencias expuestas de un modo uniforme. Esto, sin embargo, no logra disminuir la calidad narrativa de Antinucci, que es sumamente amena.

El autor comienza exponiendo una teorización acerca del lujo, partiendo de la premisa de que el comercio de lujo nunca se ha visto seriamente detenido, dado que las clases dominantes -de la cultura que fuesen- permanentemente buscaron (y buscan) representarse y diferenciarse del resto. Dicha afirmación conlleva que los productos de lujo sean caros, de difícil acceso y escasos. Estas características van a ser fundamentales en el sistema de representación que es la gastronomía.

Partiendo de lo anteriormente expuesto, el primer capítulo aborda el comercio, la distribución y el consumo de especias en el Mediterráneo antiguo. Salen a la luz los contactos entre Roma y la India, poniendo la lupa en el comercio bilateral realizado en enormes embarcaciones desde las costas del Mar Rojo hacia el Este.

\footnotetext{
${ }^{1}$ Francesco Antinucci es Director de Investigación en el Instituto de Ciencias y Tecnologías de la CNR. Es especialista en temas de lenguaje, aprendizaje y comunicación, especialmente en relación con las nuevas tecnologías digitales. Ha sido investigador en la Universidad de California y en el Palo Alto Research Center (PARC) de Xerox. Ha publicado ¿Colgados? ¿Qué hacen nuestros hijos con la computadora? ¿Qué Hace la computadora Con Nuestros Hijos? (2000), Comunicare nel museo (2014) y Il potere della cucina. Storie di cuochi, re e cardinali (2016).
} 
Antinucci nos introduce al mundo de la alta cocina de la Roma imperial. No escasean las citas de Plinio y Tito Livio, aunque el personaje central es Apicio. Hacia el final de este capítulo, en una invitación a la experimentación culinaria el autor reproduce algunas recetas del libro De Re Coquinaria, de Apicio² (aunque Antinucci ponga en evidencia la dificultad de atribuir dicho libro a este autor clásico), desafiando al lector y su paladar occidental del siglo XXI que quizás no tolere las combinaciones agrias, dulces y picantes de la antigua cocina mediterránea. Esta se encuentra a una enorme distancia de lo que hoy conocemos bajo el gran arco de las gastronomías mediterráneas (con gran protagonismo de la griega e italiana) dado que solo las une la presencia del pescado y las olivas, todo lo demás, son adiciones e intercambios realizados a lo largo de los siglos, especialmente durante la modernidad, como es el caso de la introducción de la fruta del tomate, originaria de América.

El capítulo dedicado a Venecia y la Edad Media nos muestra la temprana relación favorable de la serenísima república con Bizancio cuando la mayoría del mediterráneo era un "lago musulmán", hasta las Cruzadas y la fundación de los reinos cristianos en el Levante. Se trata de un Mediterráneo plagado de piratas sarracenos y de poblaciones enteras que viven de los rescates cobrados y del pillaje. Al lado de esta imagen convive la imagen comercial: los puertos de Egipto y Siria, dedicados al intercambio de los productos de Oriente. Por otra parte, paralelamente a lo explícitamente histórico, Antinucci registra las variaciones a lo largo del tiempo entre lo salado, lo dulce, lo agrio y sus combinaciones. Para esta tarea, igual que en capítulos anteriores, se centra en recetarios medievales que han llegado hasta hoy y analiza la presencia de sabores y las especias que los hacen posibles. Esto lo lleva al abordaje de numerosas preparaciones, tanto del mundo occidental como árabe. El autor deduce el nacimiento de la cocina moderna en la que la separación de lo dulce, lo salado y lo agrio es cada vez mayor, siendo el ultimo progresivamente excluido, para formar parte posteriormente de ese canon gastronómico que normalmente llamamos "lo exótico". La presencia del azúcar, producida en diversas partes del Mediterráneo como un bien de lujo, será protagonista de muchos de los platos servidos a papas y reyes durante la Edad Media.

Con notable capacidad de síntesis, en el capítulo siguiente, se narra la empresa de exploración lusitana entre los siglos XIV y XVI, que finalizan con la llegada a la India y el establecimiento de factorías en innumerables enclaves orientales, desde Timor hasta Macao. Al ascenso portugués le sigue la aparición en escena de los Países Bajos, recientemente independizados de los Habsburgo, y de Inglaterra. Estas potencias lucharan a lo largo del siglo XVII por definir sus esferas de influencia, especialmente en el Indico, fundando compañías privilegiadas de comercio con las Indias Orientales (V.O.C. y E.I.C. por sus siglas en holandés e inglés). Las llamadas Islas de las Especias

\footnotetext{
2 En torno al libro atribuido a Apicio, en español escasean ediciones. Sin embargo, la editorial Alba ha publicado una versión en 2006, destinada a gastrónomos y amantes de la cocina, lejos de ser un exhaustivo trabajo filológico o histórico.
} 
(las Molucas y las islas de Banda, Ceram y Ambon) serán el escenario de mayor conflicto durante este siglo.

Antinucci, retomando la cuestión gastronómica de la implementación de las especias conseguidas por las potencias, plantea que a diferencia de lo que podría creerse, en el Renacimiento no hay una revolución gastronómica (el autor insiste en que la continuidad con las tradiciones gastronómicas medievales es total), sino que lo más parecido a un cambio de paradigma en torno a lo alimenticio en tanto código simbólico sucede recién en el siglo XVII, una vez que las especias más raras se asientan en Europa. El caso paradigmático, narrado con gran astucia por Antinucci, es la caída del precio de la pimienta. Un cargamento descomunal arriba a Inglaterra en 1603 (2017, p. 98) y este no se vende. Se necesitan meses y una rebaja del precio para dar salida a toda esa pimienta, algo sin precedentes. Es en este momento cuando el foco de las compañías cambia hacia las especias finas, mucho más difíciles de conseguir, tales como la nuez moscada y el clavo de olor. Comienzan entonces a fluir hacia Europa en cargamentos cada vez mayores, dando ingentes beneficios a quienes comercian con ella, al eliminarse los intermediarios orientales

Estas reflexiones acerca de la caída en desgracia de la pimienta en el siglo XVII son quizás, la parte más interesante del libro, acercándonos a la conclusión que sacaron los perplejos comerciantes del momento: el mercado había sido inundado de dicha especia, una capa cada vez más amplia de la sociedad podía acceder a ella. Esto provocó que la pimienta rompiera la regla primordial del bien de lujo: su exclusividad $y$, por ende, su precio elevado.

Finalmente se abordan las bebidas calientes. Tan comunes para nosotros hoy en día son el té, el chocolate y el café, quienes ocupan el epílogo. Se alega que, aunque no se traten de especias, sí son productos en un principio exóticos y que llegan para quedarse. Se rastrea el origen de dichas plantas y se detalla el recorrido hasta los paladares europeos, quienes en su mayoría las desprecian en un comienzo, llegando a gestarse enormes campañas para la prohibición del café y el cacao por parte de los sectores más poderosos de las sociedades occidentales. Esto se revierte en el siglo XVII, pasando a un consumo que no ha parado de crecer hasta hoy. Desde una mirada contemporánea, esto puede no parecer gran cosa, pero el autor resalta que es notorio que el ascenso de estas bebidas permitiera a una gran parte de la sociedad occidental reducir el consumo de alcohol. Hasta el momento el común de la gente ingería alcohol diariamente en una cantidad que hoy nos resulta inconcebible y peligrosa. Esto se debía a muchos factores, especialmente a la imposibilidad de garantizar la potabilidad del agua, mientras que, en una infusión, el hervor es necesario. Además, el autor menciona que:

Lo que se modifica radicalmente con el arribo del café, el té y el chocolate es, en cambio, su modo de funcionar y de integrarse al circuito social, que no llega más a través de un código gastronómico que los coloca sobre una mesa preparada, símbolo de riqueza y estatus social. La frecuentación del café es 
una institución muy diferente a la del banquete: al café se va sobre todo para figurar, presenciar, discutir y hacerse apreciar por lo que se dice, por las propias opiniones o por el propio conocimiento, para encontrar personas valiosas con las cuales interactuar y, eventualmente, hacerse aliados: en suma, para una vida social nueva, diferente, moderna (2017, p. 129).

Como puede verse en la cita anterior, la creación de espacios de sociabilidad toma protagonismo en el epílogo, donde se enumeran los cafés parisinos y londinenses, donde estos establecimientos se especializarán en agrupar comerciantes, literatos, hombres de ciencia y políticos. De esta manera, se visibiliza el ascenso de la burguesía europea.

Por otra parte, la enorme difusión de estas plantas llevadas a cabo por los europeos durante los siglos XVII y XVIII, tal como señala Antinucci (2017, p.129), han terminado por confundir al público en general acerca de su origen. Circula una especie de creencia arraigada acerca de que el café es sudamericano; el té, de la India y el cacao, africano.

Llama la atención que la esclavitud requerida para la producción de dichas mercancías (y sin la cual nada de lo narrado a lo largo de este libro hubiera sido posible) sea mencionada únicamente cuando se habla de agricultura extensiva (haciendo referencia a las plantaciones de café, té y cacao). Es aquí cuando el autor, a pocas páginas del final, menciona que el tema es "de gran interés e importancia" (2017, p. 130), pero que no entra dentro del horizonte del libro, el cual se centra en el análisis de los recetarios de época. Esto genera una leve incomodidad, dado el minúsculo espacio dedicado al tema (se trata de escasos renglones). El autor corre el riesgo de que la delimitación brusca del tema sea confundida con el desinterés. Esto contribuye a que, al finalizar el libro, uno tiene la sensación de que la narración ha transcurrido más en la mesa de burgueses, nobles y clérigos que en las selvas asiáticas y americanas, priorizándose un detallado recorrido a través de recetarios, especialmente modernos. En otras palabras, el autor se explaya en el consumo culinario derivado de la aplicación de las especias, mucho más de lo que lo hace con respecto a los lugares y condiciones de producción, comercio de las mismas y cambios producidos en las economías orientales y occidentales. En resumidas cuentas, nos encontramos con un pantallazo mayormente culinario, dedicado a un público general, de la historia de los sabores en Occidente hasta el siglo XIX y sus "curiosos" orígenes. En cambio, quien pretenda analizar en mayor profundidad la producción y el comercio de especias durante la era moderna es recomendable que aborde los trabajos de Parry (1993), Fieldhouse (1984), Mauro (1973) y Chaunu (1973), entre otros.

\section{Referencias bibliográficas}

Antinucci, F. (2000). ¿Colgados? ¿Qué hacen nuestros hijos con la computadora? ¿Qué hace la computadora con nuestros hijos? Buenos Aires: Fondo de Cultura Económica. 
Antinucci, F. (2014). Comunicare nel museo. Bari: Laterza Editori.

Antinucci, F. (2016). Il potere della cucina. Storie di cuochi, re e cardinali. Bari: Laterza Editori.

Chaunu, P. (1973). Conquista y explotación de los nuevos mundos. Barcelona: Editorial Labor.

Fieldhouse, D. K. (1984). Los imperios coloniales desde el siglo XVIII. Madrid: Siglo XXI Editores.

Mauro, F. (1973). La expansión europea (1600-1870). Barcelona: Editorial Labor.

Parry, J. H. (1993). Europa y la expansión del mundo, 1415-1715. Buenos Aires: Fondo de Cultura Económica.

Re, A. A. del (2006). Apicio. De Re Coquinaria: Antología de recetas de la Roma imperial. Traducción de J. Barría Aguiló. Barcelona: Alba Editorial.

\section{Ignacio Liziardi}

Universidad Nacional de Córdoba igna_liziardi@yahoo.com

Para citar esta reseña:

Liziardi, Ignacio (2021): Reseña bibliográfica, "Antinucci, F. (2017). Especias. Una historia de descubrimiento, codicia y lujo, Buenos Aires: Edhasa, 142 pp." Anuario de la Escuela de Historia Virtual 19, 183-187. 